\title{
EVALUASI KERENTANAN BANGUNAN GEDUNG TERHADAP GEMPA BUMI BERDASARKAN ASCE 41-13
}

\author{
Hanantatur Adeswastoto \\ Mahasiswa Magister Teknik Sipil Universitas Riau \\ Jalan Subrantas Km 12,5 Pekanbaru, 28293 \\ E-mail : hanantatur@student.unri.ac.id \\ Zulfikar Djauhari \\ Magister Teknik Sipil Universitas Riau \\ Jalan HR. Soebrantas Panam Pekanbaru \\ E-mail : zulfikar.djauhari@lecturer.unri.ac.id \\ Reni Suryanita \\ Magister Teknik Sipil Universitas Riau \\ Jalan Subrantas Km 12,5 Pekanbaru, 28293 \\ E-mail : reni.suryanita@ lecturer.unri.ac.id
}

\begin{abstract}
Abstrak
Gedung Menara Lancang Kuning merupakan salah satu bangunan bertingkat tinggi di Pekanbaru yang memiliki kerentanan yang cukup besar terhadap gempa. Bangunan ini harus dapat bertahan terhadap gempa agar resiko bahaya yang terjadi dapat diminimalisir. Penelitian ini bertujuan untuk mengetahui kerentanan bangunan gedung terhadap gempa bumi. Dalam penelitian ini dilakukan evaluasi berdasarkan ASCE 4113. Evaluasi Tahap 1 pada ASCE 41-13 merupakan metode evaluasi cepat sehingga dapat menjadi acuan untuk evaluasi tahap selanjutnya. Evaluasi dimulai dengan menentukan tingkat bencana, tingkat seismisitas, dan penentuan tingkat kinerja. Hasil penelitian menunjukkan bahwa bangunan Gedung Lancang Kuning memenuhi tingkat kinerja yang menjadi acuan.
\end{abstract}

Kata Kunci : $\quad$ ASCE 41-13, Evaluasi Tahap 1, Gedung, Kerentanan

\begin{abstract}
Menara Lancang Kuning building is one of the high-rise buildings in Pekanbaru that has considerable vulnerability to earthquakes. This building must be able to withstand earthquakes so that the risk of danger that occurs can be minimized. This study aims to determine the vulnerability of buildings to earthquakes. In this study was evaluated based on ASCE 41-13. The Tier 1 evaluation of ASCE 41-13 is a rapid evaluation method so it can become a reference for next stage evaluation. Evaluation begins by determining the level of Seismicity Hazard, the level of seismicity, and determining the level of performance. The results showed that the building of Menara Lancang Kuning meets the level of performance that become the reference.
\end{abstract}

Keywords : ASCE 41-13, Tier 1 Evaluation, Building, Vulnerability 


\section{A. PENDAHULUAN}

Gempa bumi merupakan kejadian alam yang tidak dapat diketahui kapan akan terjadi dan seberapa besarnya, dan dapat menimbulkan kerugian yang dapat berupa jiwa maupun harta. Di Indonesia, gempa bumi yang terjadi sebagian besar menimbulkan korban jiwa, misalnya gempa bumi di Aceh pada 26 Desember 2004, yang menelan korban lebih dari 200.000 jiwa, kemudian gempa bumi di Yogyakarta pada 27 Mei 2006, dengan korban lebih dari 6.000 jiwa, dan di Padang pada 30 September 2009 menelan korban lebih dari 6.000 jiwa.

Korban jiwa akibat gempa tersebut biasanya tidak diakibatkan oleh gempa bumi secara langsung, melainkan diakibatkan oleh bangunan yang runtuh ketika gempa terjadi. Keruntuhan bangunan ketika gempa terjadi akan mengenai orang yang berada didalam bangunan sehingga menyebabkan korban luka hingga meninggal dunia. Hal ini menyebabkan semakin meningkatnya kebutuhan bangunan yang tahan terhadap gempa. Dengan bangunan yang tahan gempa maka korban jiwa akibat adanya gempa dapat diminimalkan.

Bangunan gedung pada daerah yang rawan gempa harus dapat bertahan terhadap gempa agar resiko bahaya yang terjadi dapat diminimalisir. Untuk memastikan apakah suatu bangunan gedung memerlukan analisis lebih lanjut berkaitan dengan ketahanannya terhadap gempa maka diperlukan suatu evaluasi tahap awal. Untuk mengevaluasi kerentanan bangunan terhadap gempa dapat dilakukan evaluasi berdasarkan ASCE 41-13. Bangunan yang rentan gempa dianalisis menggunakan metode evaluasi Tahap 1 atau Tier 1 sehingga dapat dijadikan acuan untuk penanganan lebih lanjut.
Penelitian ini melakukan evaluasi berdasarkan ASCE 41-13 untuk bangunan di Indonesia terutama Pekanbaru. Penggunaan metode ini dimaksudkan untuk melihat apakah evaluasi berdasarkan ASCE 41-13 dapat diterapkan di Indonesia, sehingga bisa dijadikan bahan pertimbangan untuk menjadi pedoman mengenai sistem penilaian gedung terhadap kerentanan gempa yang sesuai dengan peraturanperaturan yang ada dan bisa di terapkan di Indonesia.

\section{B. TINJAUAN PUSTAKA}

\section{Gempa Bumi}

Gempa bumi adalah getaran atau guncangan yang terjadi di permukaan bumi akibat pelepasan energi dari dalam secara tiba-tiba yang menciptakan gelombang seismik (BMKG, 2016). Gempa Bumi biasa disebabkan oleh pergerakan kerak Bumi (lempeng Bumi). Frekuensi suatu wilayah, mengacu pada jenis dan ukuran gempa Bumi yang di alami selama periode waktu.

\section{ASCE 41-13}

ASCE 41-13 menggabungkan ASCE 31-03 ke ASCE 41-06 sekaligus memperbarui kedua standar tersebut. Standar gabungan terbaru menghilangkan inkonsistensi yang sebelumnya ada antara kedua standar.

Saat ini pengguna standar ini dapat memutuskan apakah akan melanjutkan dengan sasaran kinerja yang lebih rendah, biasanya digunakan untuk bangunan eksisting, seperti yang digunakan dalam ASCE 31 atau ancaman bahayanya sama dengan gedung baru, mirip dengan Sasaran Keselamatan Dasar di ASCE 41. Selain itu, pengecekan Tahap 1 atau Tier 1 telah dimodifikasi secara signifikan dan dirombak ulang. 
Dalam ASCE 41-13 ada empat tingkatan kinerja bangunan (dari rendah ke tinggi) yaitu Collapse Prevention (5E), Life Safety (3-C), Immediate Occupancy (1-B) dan Operational (1A). Mayoritas bangunan dirancang untuk tingkat kinerja Life Safety (LS), kecuali jika dibutuhkan oleh peraturan misalnya layanan darurat, penjara, atau fasilitas penting lainnya, tingkat kinerja LS dimaksudkan untuk menjamin keselamatan penghuni bangunan. Namun bangunan dengan tingkat kinerja ini kemungkinan akan mengalami kerusakan yang signifikan yang bisa saja tidak diperbaiki atau ditempati setelah gempa.

Untuk fasilitas penting yang harus mempertahankan fungsinya pasca gempa untuk memberikan layanan darurat kepada masyarakat, seperti stasiun pemadam kebakaran, bangunan dievaluasi dengan standar yang lebih tinggi dari Operational. Perlu dicatat bahwa kriteria Operational dan Immediate Occupancy sama untuk evaluasi struktural.

\section{Analisis Tahap 1}

Tujuan dari evaluasi Tahap 1 adalah untuk mengidentifikasi bangunan yang memenuhi ketentuan standar ini dengan cepat. Selain itu juga membiasakan para peneliti dengan desain dari suatu bangunan, potensi kekurangan serta perilakunya. Evaluasi lebih lanjut menggunakan evaluasi Tahap 2 atau Tahap 3 kemudian berfokus pada kekurangan potensial yang teridentifikasi dalam Tahap 1. Sebagai alternatif, peneliti desain dapat memilih untuk mengakhiri penyelidikan dan melaporkan kekurangan atau setelah berkonsultasi dengan pemilik, dapat memilih untuk melanjutkan ke desain retrofit tanpa melakukan evaluasi Tahap 2 atau Tahap 3.
Berikut adalah bagian-bagian pada evaluasi tahap 1 yaitu :

a. Tingkat Kinerja

Tingkat sasaran kinerja ditetapkan sebelum melakukan evaluasi seismik menggunakan standar ini. Sasaran kinerja ditentukan oleh pemilik berkonsultasi dengan peneliti dan dengan instansi yang berwenang. Evaluasi Tahap 1 dapat dilakukan untuk salah satu atau keduanya dari Sasaran Kinerja Bangunan yaitu Life Safety (S-3, NC) dan Immediate Occupancy (S-1, N-B).

b. Tingkat Bahaya Seismik

Tingkat bahaya seismik untuk evaluasi Tahap 1 harus sesuai dengan BSE-1E sesuai dengan kinerja tujuan dasar untuk bangunan eksisting (Basic Performance Objective for Existing Buildings, BPOE).

c. Tingkat Seismisitas

Tingkat seismisitas bangunan didefinisikan sebagai sangat rendah (Very Low), rendah (Low), sedang (Moderate), atau tinggi (High). Pengecekan lapangan dan evaluasi Tahap 1 diizinkan berdasarkan pada dokumen konstruksi yang tersedia dan catatan lainnya, mengacu pada temuan penyelidikan di lokasi. Penyelidikan di lokasi dilakukan untuk memverifikasi kesesuaian kondisi yang ada dengan yang dijelaskan dalam dokumen yang ada, untuk mengidentifikasi perubahan dokumen yang ada, untuk melengkapi dokumen yang tidak lengkap, untuk mengkonfirmasi kualitas pembangunan dan pemeliharaan, serta hal lain yang diperlukan untuk menyelesaikan evaluasi Tahap 1.

Jika diperlukan, penelitian dapat mengambil sampel dari bangunan 
dengan tidak merusak bangunan tersebut. Penyelidikan di lokasi meliputi penyelidikan umum, cacat konstruksi, atau kerusakan yang dapat memiliki efek yang signifikan pada kinerja seismik. Temuan dan dokumentasi penyelidikan ini harus mendapat persetujuan dari instansi yang berwenang jika diperlukan.

d. Jenis Bangunan

Jenis bangunan diklasifikasikan berdasarkan satu atau lebih jenis bangunan, berdasarkan sistem penahan tekanan lateral dan jenis diafragma. Jenis bangunan terpisah digunakan untuk bangunan dengan sistem penahan tekanan lateral dalam arah yang berbeda.

Ceklist terpisah untuk masingmasing jenis bangunan yang termasuk dalam standar ini serta daftar periksa struktur secara umum untuk bangunan yang tidak sesuai dengan deskripsi dari jenis bangunan umum.

e. Nilai Material Standar

Penggunaan nilai standar diperbolehkan untuk sifat material pada evaluasi Tahap 1. Nilai standar dapat berupa asumsi kecuali dinyatakan berbeda oleh dokumen konstruksi yang ada atau dengan pengujian. Properti standar material ketika mengevaluasi bangunan menggunakan standar ini, maka peneliti harus:

1).Mencari laporan geoteknik yang ada pada kondisi tanah pada lokasi

2).Membuat parameter tanah dan lokasi

3).Mengumpulkan data desain bangunan, termasuk gambar kontrak, spesifikasi, dan perhitungan
4).Mencari data lain, seperti penilaian kinerja bangunan selama gempa bumi sebelumnya

5).Memilih dan meninjau peralatan yang sesuai dari laporan evaluasi

f. Tolok Ukur Bangunan

Evaluasi seismik struktur menggunakan standar ini tidak perlu dilakukan untuk bangunan yang dirancang, dibangun atau dievaluasi sesuai dengan ketentuan standar ini. Namun, evaluasi elemen nonstruktural masih diperlukan. Bangunan yang memenuhi ketentuan bagian ini memenuhi BSE-1E untuk menentukan tingkat kinerja.

g. Dokumen Eksisting

Review gambar bangunan struktur dilakukan untuk mengkonfirmasi bahwa unsur-unsur utama dari sistem penahan gempa dan didesain sesuai dengan ketentuan yang berlaku.

Peneliti menentukan bahwa bangunan memenuhi ketentuan umum dengan acuan standar ASCE. Hal ini dilakukan karena terkadang bangunan tidak memiliki rincian yang dapat digunakan untuk memenuhi ketentuan atau standar. Tujuannya dengan mengharuskan peneliti mengevaluasi untuk mempertimbangkan desain aktual dari struktur, bukan hanya aturan yang dikatakan telah diterapkan. Bahkan dengan persyaratan ini, diharapkan sebagian besar bangunan yang memenuhi syarat untuk pembandingan tidak memerlukan tinjauan perhitungan secara rinci.

h. Verifikasi Lapangan

Verifikasi lapangan dilakukan untuk memastikan bahwa bangunan dibangun sesuai dengan gambar dan tidak ada modifikasi yang mempengaruhi kinerja. 
Peneliti memastikan data bangunan dengan mengunjungi lokasi, karena terkadang bangunan eksisting dibangun untuk peruntukan yang berbeda dengan desain awal atau telah berubah peruntukannya. Selain itu kualitas pembangunan yang rendah juga mempengaruhi desain awal.

i. Bahaya Geologi pada Lokasi

Sebisa mungkin tidak ada pencairan tanah, longsor, atau kerusakan permukaan di lokasi proyek. Atau, jika terjadi bencana, dapat diminimalisir dengan desain sistem penahan tekanan lateral, termasuk pondasi. Bahkan jika sebuah bangunan yang ada dirancang dengan benar dan dibangun sesuai aturan, kondisi suatu lokasi tidak secara eksplisit ditentukan oleh aturan. Gerakan dasar besar disebabkan oleh sejumlah bahaya lokasi sehingga dapat merusak sebuah bangunan dinyatakan tahan gempa. Potensi penyebab gerakan dasar termasuk gerakan kedalam atau keluar yang disebabkan oleh pencairan tanah, longsor, atau kerusakan permukaan tanah.

Jika terdapat ancaman bahaya geologi pada lokasi, desain penahan tekanan bangunan sedapat mungkin dapat mengantisipasi bahaya tersebut, seperti penggunaan pondasi dalam pada area berpotensi terjadi pencairan tanah.

\section{DATA DAN ANALISA DATA}

\section{Data Penelitian}

a. Penentuan Tingkat Bencana Seismik Kinerja tujuan dasar untuk bangunan eksisting (Basic Performance Objective for Existing Buildings, $B P O E)$ merupakan tujuan kinerja tertentu dengan kategori risiko bervariasi. Prosedur Tahap 1, digunakan untuk menunjukkan kesesuaian dengan BPOE.

Bangunan Gedung Menara Lancang Kuning ini di evaluasi berdasarkan nilai spektral percepatan di permukaan dari gempa risk-targeted maximum consider earthquake dengan probabilitas keruntuhan bangunan $1 \%$ dalam 50 tahun (Puskim.pu.go.id, 2017).

b. Penentuan Tingkat Seismisitas Tingkat seismisitas lokasi tergantung lokasi dan berdasarkan tingkatan dari ASCE 41-13. Untuk bangunan Gedung Menara Lancang Kuning memiliki nilai $\mathrm{SDS}=0,421$ dan SD1=0,331 (Puskim.pu.go.id, 2017). Dari data tersebut, berdasarkan data ASCE 41-13 tentang level seismisitas pada tabel 1, maka bangunan gedung berada di area dengan tingkat seismisitas tinggi.

c. Penentuan Tingkat Kinerja

Tingkat kinerja didefinisikan sebelum melakukan evaluasi seismik dengan standar ASCE 41-13. Pada dasarnya, tingkat kinerja ditentukan oleh pemilik gedung untuk mengetahui sejauh mana kemampuan gedung terhadap gempa. Bangunan gedung berada pada tingkat seismisitas tinggi dilakukan evaluasi dengan tingkat kinerja Immediate Occupancy.

\section{Formulir Evaluasi Tahap 1}

Dalam penelitian ini pengolahan data menggunakan formulir yang ada pada ASCE 41-13 sesuai dengan karakteristik bangunan, yakni kombinasi dari C1, Beton Konstruksi Rangka dan C2, Beton Konstruksi Dinding Geser dengan Diafragma Kaku serta C2a, Beton Konstruksi Dinding Geser dengan 
Diafragma Fleksibel. Formulir terdiri dari lembar ringkasan data (Summary Data Sheet), checklist tahap pertama (Tier 1), dan formulir Immediate Occupancy dasar. Pada formulir C1, Beton Konstruksi Rangka dan dan C2, Beton Konstruksi Dinding Geser dengan Diafragma Kaku serta C2a, Beton Konstruksi Dinding Geser dengan Diafragma Fleksibel yang merupakan formulir Immediate Occupancy.
Formulir yang akan digunakan terdiri dari formulir Immediate Occupancy dasar. Setelah itu formulir yang akan digunakan adalah formulir yang sesuai dengan karakteristik bangunan, dimana pada penelitian ini formulir yang akan digunakan yakni formulir $\mathrm{C} 1, \mathrm{C} 2$ dan C2a. Formulir terakhir yang akan digunakan yakni formulir Non Structural Checklist.

Tabel 1. Level Seismisitas

\begin{tabular}{lcc}
\hline \multicolumn{1}{c}{ Level of Seismicity $^{a}$} & $\mathrm{~S}_{\mathrm{DS}}$ & $\mathrm{S}_{\mathrm{D} 1}$ \\
\hline Very low & $<0.167 \mathrm{~g}$ & $<0.067 \mathrm{~g}$ \\
\hline \multirow{2}{*}{ Low } & $\geq 0.167 \mathrm{~g}$ & $\geq 0.067 \mathrm{~g}$ \\
& $<0.33 \mathrm{~g}$ & $<0.133 \mathrm{~g}$ \\
\hline \multirow{2}{*}{ Moderate } & $\geq 0.33 \mathrm{~g}$ & $\geq 0.133 \mathrm{~g}$ \\
& $<0.50 \mathrm{~g}$ & $<0.20 \mathrm{~g}$ \\
\hline High & $\geq 0.50 \mathrm{~g}$ & $\geq 0.20 \mathrm{~g}$ \\
\hline${ }^{a}$ The higher level of seismicity defined by $S_{D S}$ or $S_{D 1}$ shall govern \\
\hline
\end{tabular}

(Sumber : ASCE 41-13, 2014)

\section{HASIL DAN PEMBAHASAN}

\section{Konfigurasi Dasar Immediate Occupancy}

a. Jalur Beban

Gedung Lancang Kuning memiliki jalur beban yang lengkap dan terdefinisi dengan baik, termasuk elemen struktur dan sambungannya, yang berfungsi untuk mentransfer kekuatan inersia yang terkait dengan massa semua elemen bangunan ke pondasi.

Pada gambar 1 pondasi gedung dan 2 (gambar 2 tipikal dari lantai 1 sampai 8) kolom dan balok gedung menggambarkan bahwa kekuatan seismik yang berasal dari seluruh bangunan dihantarkan melalui sambungan struktural ke diafragma horisontal. Diafragma menyalurkan kekuatan ke elemen vertikal dari sistem penahan gaya seismik, seperti dinding geser dan rangka. Elemen vertikal memindahkan kekuatan ke pondasi, dan pondasi memindahkan kekuatan ke tanah pendukung. Hal ini menunjukkan adanya jalur beban yang lengkap dan bahwa semua elemen dan koneksi di dalam jalur beban tampaknya diperinci untuk mentransfer kekuatan seismik.

b. Bangunan yang Berdekatan

Pada Gedung Lancang Kuning ini terdapat bangunan yang lama yang berfungsi sebagai perkantoran. Jarak antara bangunan yang dievaluasi dan bangunan yang berdekatan lebih dari 4\% dibandingkan tinggi bangunan yang lebih rendah. Tinggi bangunan yang lebih rendah $\pm 12 \mathrm{~m}$, dengan jarak ke Gedung yang baru $\pm 16 \mathrm{~m}$. Maka jarak antara bangunan yang dievaluasi dan bangunan yang berdekatan lebih dari $4 \%$ dibandingkan tinggi bangunan yang lebih rendah. 


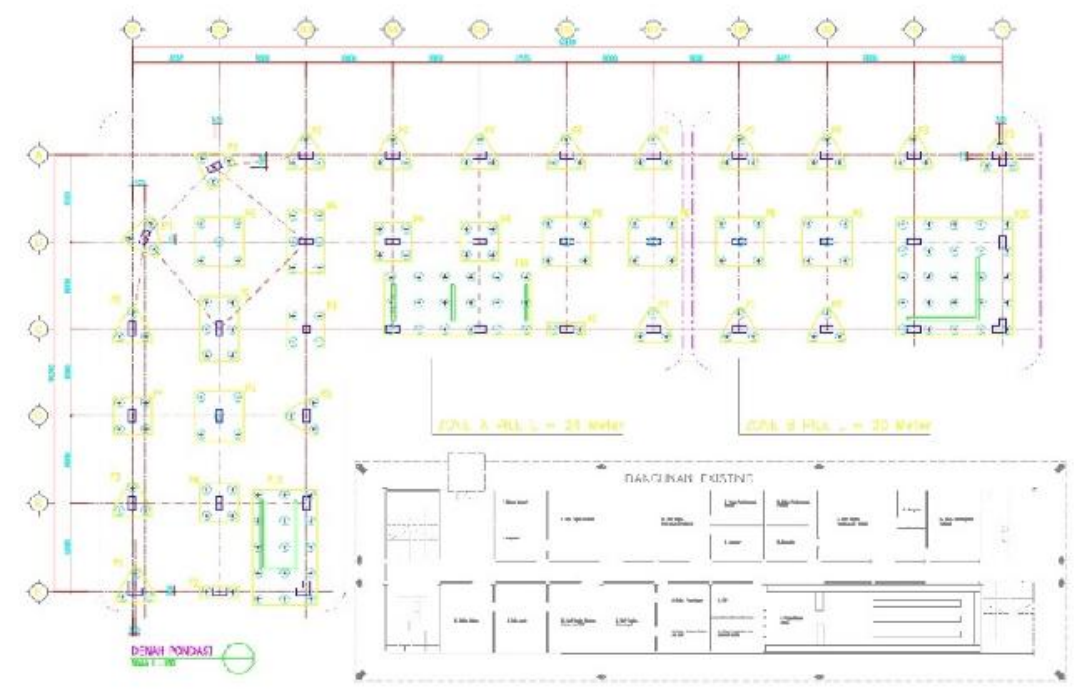

Gambar1. Denah Pondasi Gedung

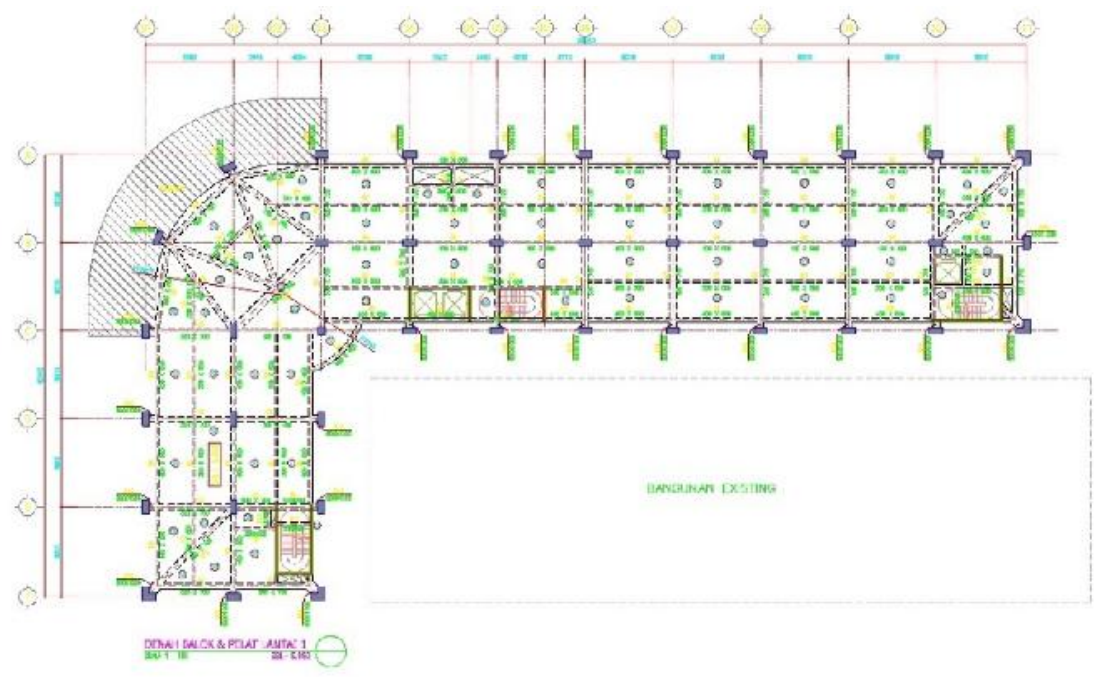

Gambar 2. Denah Gedung

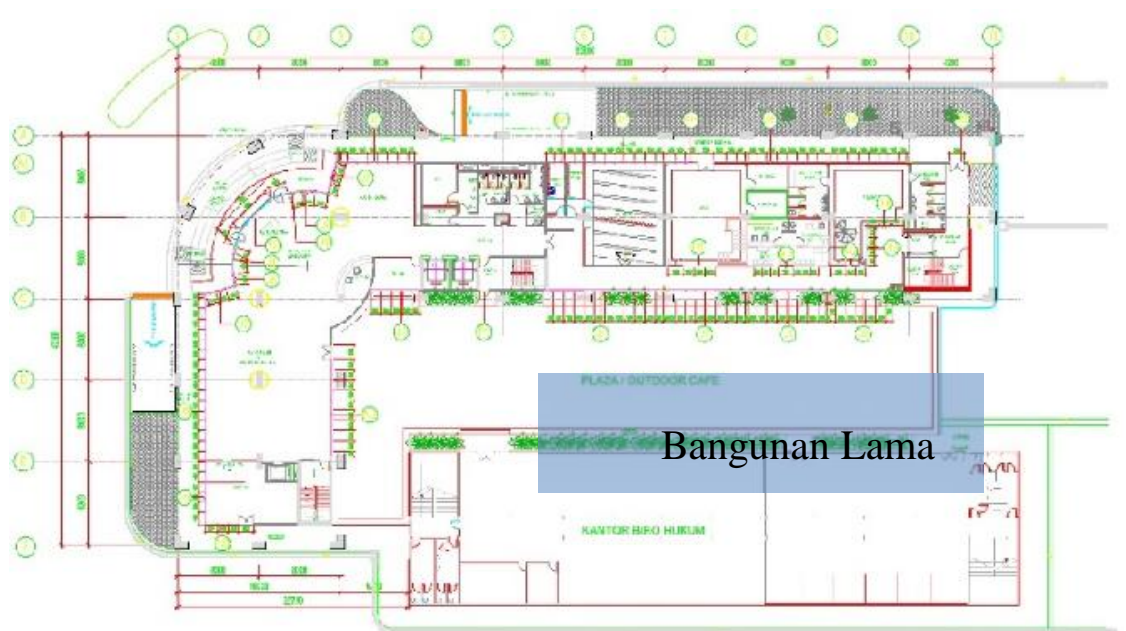

Gambar 3. Bangunan Lama yang Berdekatan dengan Gedung 


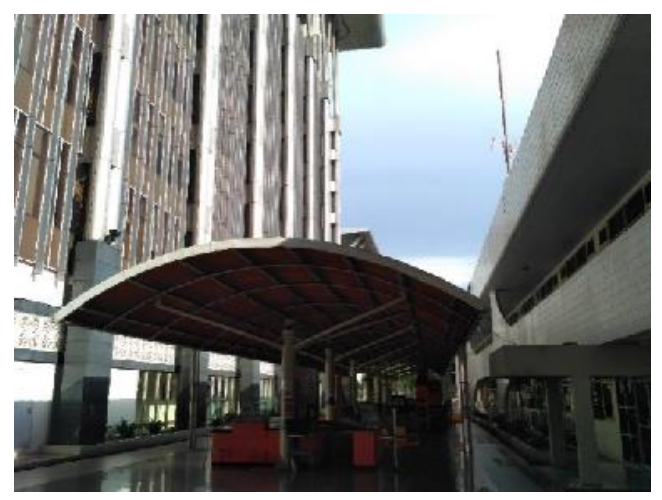

Gambar 4. Bangunan yang Berdekatan

c. Lantai Mezzanine

Pada Gedung Lancang Kuning ini terdapat lantai mezzanine yang diperkuat secara terpisah dari struktur utama atau dilekatkan pada elemenelemen yang menahan gaya seismik dari struktur utama seperti pada gambar 5, sehingga mampu menahan gaya seismik ketika terjadi gempa.

d. Kemiringan Lereng

Lokasi bangunan gedung terletak pada lokasi yang relatif datar sehingga kecil kemungkinan terjadi kegagalan akibat gempa dan tidak terpengaruh oleh kegagalan tersebut serta mampu mengakomodasi pergerakan yang diprediksi tanpa terjadi kegagalan bangunan.

e. Retak pada Permukaan

Pada lokasi bangunan gedung, tidak ditemui adanya retakan yang dapat mengakibatkan kegagalan pada bangunan gedung.

f. Ikatan antar Elemen Pondasi

Pondasi pada bangunan Gedung Lancang Kuning memiliki ikatan yang cukup untuk menahan kekuatan seismik, dimana pondasi bangunan gedung menggunakan pancang dengan kedalaman $24 \mathrm{~m}$ dan $20 \mathrm{~m}$.

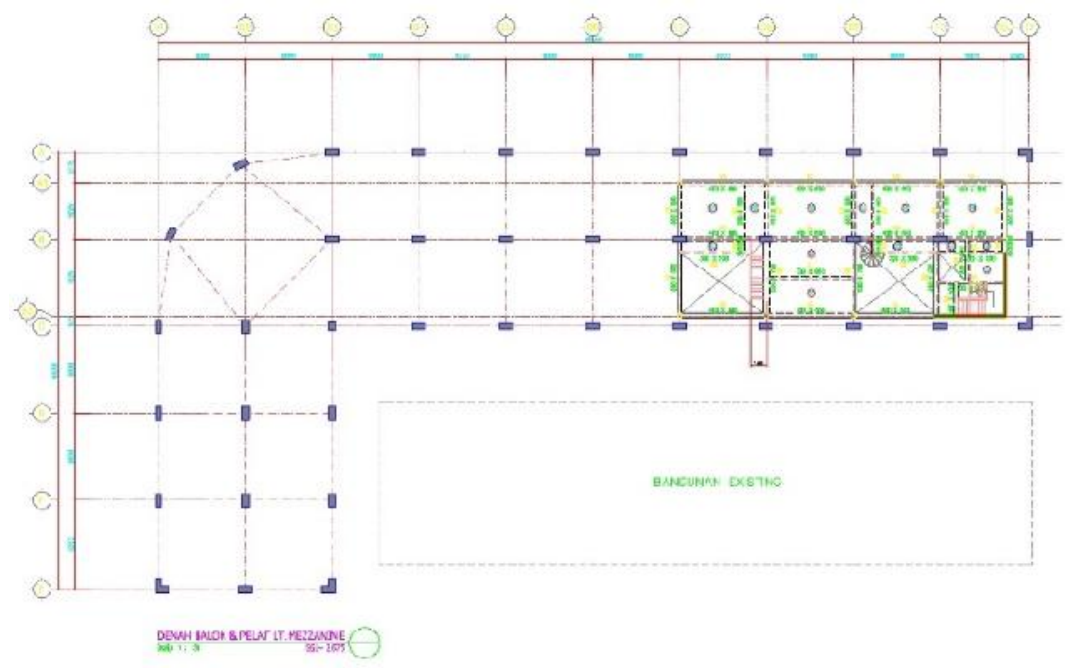

Gambar 5. Denah Lantai Mezzanine 


\section{Evaluasi Struktural Immediate Occupancy Untuk Bangunan Tipe C1: Beton Konstruksi Rangka}

a. Rangka Plat Datar

Pada bangunan gedung, sistem penahan gaya gempa bukan merupakan rangka yang terdiri dari kolom dan plat datar tanpa balok. Sistem penahan gaya seismik mentransfer gaya gempa melalui kolom dan balok. Jika hanya terdiri dari kolom dan plat maka akan terjadi pembengkokan struktur.

b. Kolom Tertahan (Kolom Pendek) Pada bangunan gedung, tinggi kolom sama pada satu lantai tidak terdapat kolom dengan rasio tinggi atau kedalaman kurang dari $75 \%$ pada setiap lantai bangunan. Hal ini penting karena jika terdapat perbedaan maka tingkat kelenturan tiap lantai akan menjadi berbeda.

c. Tidak Terdapat Kegagalan Geser

Sengkang pada struktur bangunan gedung mencegah kegagalan geser yang getas pada balok beton bertulang dengan membatasi retak geser diagonal dan dengan melindungi beton dari menonjol keluar (bulging outward) akibat lentur. Sengkang juga menyediakan pengekangan dan mencegah terjadinya tekuk pada tulangan longitudinal yang tertekan.

Kapasitas geser dari rangka bangunan gedung dikatakan mampu untuk menahan kapasitas momen di ujung rangka. Jika kapasitas geser dari anggota tercapai sebelum kapasitas momen, ada potensi untuk kegagalan non elastis tiba-tiba, yang menyebabkan keruntuhan.

d. Kolom Kuat-Balok Lemah

Pada bangunan Gedung Lancang Kuning ini, kolom (yang menerima gaya dari balok) memiliki kuat lentur yang lebih besar dibandingkan balokbaloknya, dan pondasi (yang menerima gaya dari kolom) lebih kuat daripada kolomnya. Kolom dapat dibuat lebih besar kuat lenturnya dibandingkan balokbaloknya dengan cara merencanakannya berpenampang yang lebih besar dan dengan jumlah baja tulangan longitudinal yang lebih banyak dibandingkan baloknya.

Sambungan antara balok dan kolom juga antara kolom dan pondasi direncanakan sedemikian agar keruntuhan dapat dihindari, sehingga diyakini bahwa gaya-gaya dapat ditransfer dengan aman di antara elemen-elemen tersebut

Gedung memiliki kapasitas momen dari kolom 20\% lebih besar dari balok pada sambungan rangka. Jika kolom tidak cukup kuat menahan balok maka akan terjadi ketidakstabilan pada rangka.

e. Balok

Pada bangunan gedung memiliki lima balok membujur. Hal ini menjadikan bangunan gedung dapat terhindar dari kemungkinan keruntuhan bangunan.

Tulangan longitudinal terdapat sepanjang balok untuk menahan retak lentur pada permukaan balok yang disebabkan oleh tarik. Jika beban gravitasi sudah diketaui arah bebannya, maka gaya lateral mempunyai arah yang berubah ubah selama terjadi getaran tanah akibat gempa. Hal ini menyebabkan baik permukaan atas maupun bawah balok mengalami tarik dan membutuhkan tulangan longitudinal

f. Eksentrisitas Sambungan

Tidak ada eksentrisitas yang lebih besar dari $20 \%$ dari rencana kolom terkecil antara garis tengah kolom dan balok penopang. Penyambungan 
dihindari pada daerah di mana tulangan longitudinal diharapkan akan mengalami leleh akibat tarik. Tulangan atas disambung pada area sepertiga bentang balok

g. Sengkang dan Pengikat

Pada struktur bangunan Gedung Lancang Kuning, semua sengkang tertutup memiliki kait bersudut $135^{\circ}$ yang ditempatkan pada posisi berlawanan antara sengkang yang satu terhadap sengkang lain di sebelahnya. Sengkang-sengkang seperti ini tidak terbuka selama guncangan gempa karena ujung sengkang tertanam pada bagian inti penampang balok yang terkekang.

h. Kesesuaian Lentur

Komponen sekunder memiliki kapasitas geser untuk memperkuat kekuatan lentur dari komponen dan sesuai dengan item berikut: sambungan kolom, sambungan balok, sambungan pengikat, sambungan sengkang, dan pengait sengkang dan pengikat. i. Plat Datar

Plat datar bukan merupakan bagian dari sistem penahan gempa yang memiliki baja menerus ke bawah melalui sendi kolom. Plat datar tidak dirancang untuk sistem penahan gempa sehingga masih mungkin mengalami gaya gempa karena perpindahan terkait dengan pergeseran bangunan secara keseluruhan

j. Diafragma Menerus

Pada bangunan gedung, diafragma terdapat pada basemen. Diafragma terputus pada ramp untuk sirkulasi parkir (Gambar 7). Terputusnya diafragma menyebabkan diafragma berfungsi sebagai kantilever. Hal ini menyebabkan terjadinya ketidakstabilan pada diafragma jika terjadi gempa.

k. Perkuatan Diafragma pada Bukaan Pada diafragma bangunan gedung, bukaan dapat meningkatkan tekanan geser. Bukaan yang relatif kecil dibandingkan ukuran diafragma secara keseluruhan, efek yang terjadi ketika gempa dapat diabaikan.

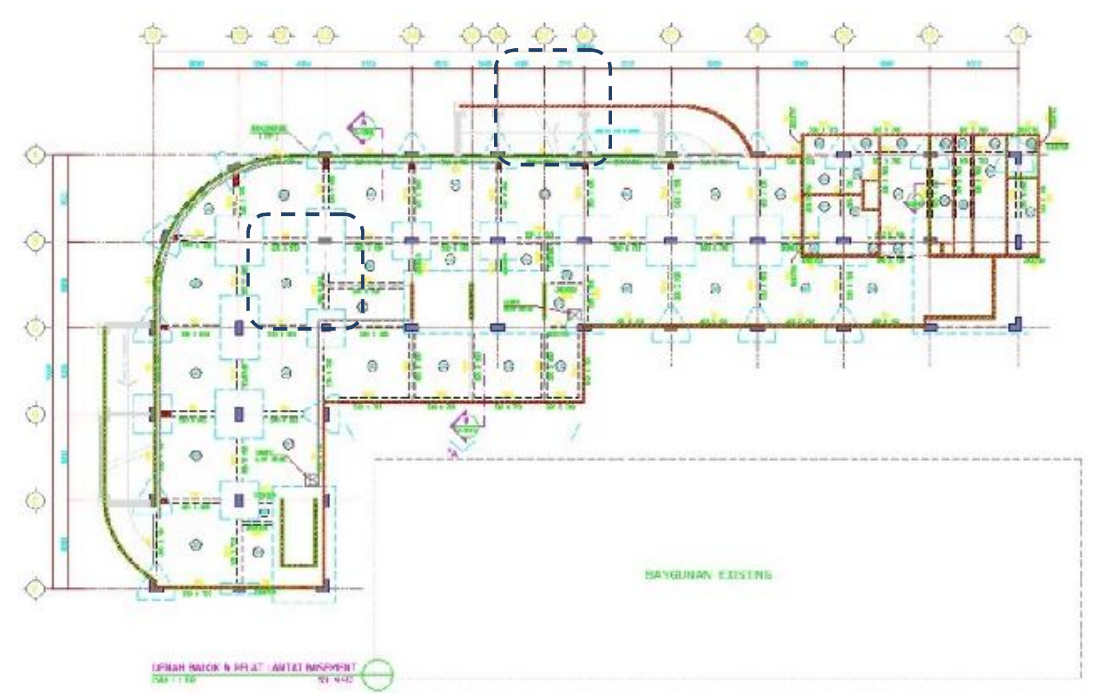

Gambar 6. Dinding Diafragma 
3. Evaluasi Struktural Immediate

Occupancy Untuk Bangunan

Tipe C2: Beton Konstruksi

Dinding Geser dengan

Diafragma Kaku dan C2a:

Beton Konstruksi Dinding

Geser dengan Diafragma

Fleksibel

a. Rangka Utuh

Pada bangunan gedung ini, terdapat sistem rangka beton yang diklasifikasikan sebagai komponen sekunder membentuk sistem penahan beban vertikal. Selama gempa, dinding geser bisa rusak oleh gaya seismik, membatasi kemampuannya untuk mendukung beban vertikal.

b. Redundansi

Jumlah baris dinding geser di setiap arah lebih besar dari atau sama dengan 2. Gambar 8 merupakan redundansi untuk bangunan dinding geser di mana ada beberapa dinding geser untuk mendistribusikan kekuatan gempa merata di seluruh struktur dan beberapa tempat di setiap gaya gempa untuk mengurangi geser dan tekanan pada setiap tiap elemen. c. Transfer ke Dinding Geser

Diafragma pada bangunan gedung ini tidak menyambung ke dinding geser, sehingga tidak terdapat jalur beban untuk transfer tekanan diafragma ke dinding geser atau rangka.

d. Pemaku Pondasi

Pada bangunan gedung, penopang dinding dipancang ke pondasi, dan pemancang mampu memberikan kekuatan yang lebih rendah dari kapasitas dinding, sehingga dinding lebih aman terhadap gempa.

e. Pondasi Dalam

Pondasi dalam pada bangunan gedung ini digunakan untuk mentransfer beban ke lapisan tanah yang lebih dalam untuk mencapai kedalam tertentu sehingga didapat jenis tanah yang mendukung daya beban struktur bangunan gedung. Tiang pancang pada bangunan gedung ini mampu mentransfer gaya gempa antara struktur dan tanah.

f. Kemiringan Lokasi

Lokasi bangunan Gedung Lancang Kuning ini berada pada lahan yang cenderung datar dan tidak berkontur, sehingga tidak terdapat perbedaan kedalaman pondasi.

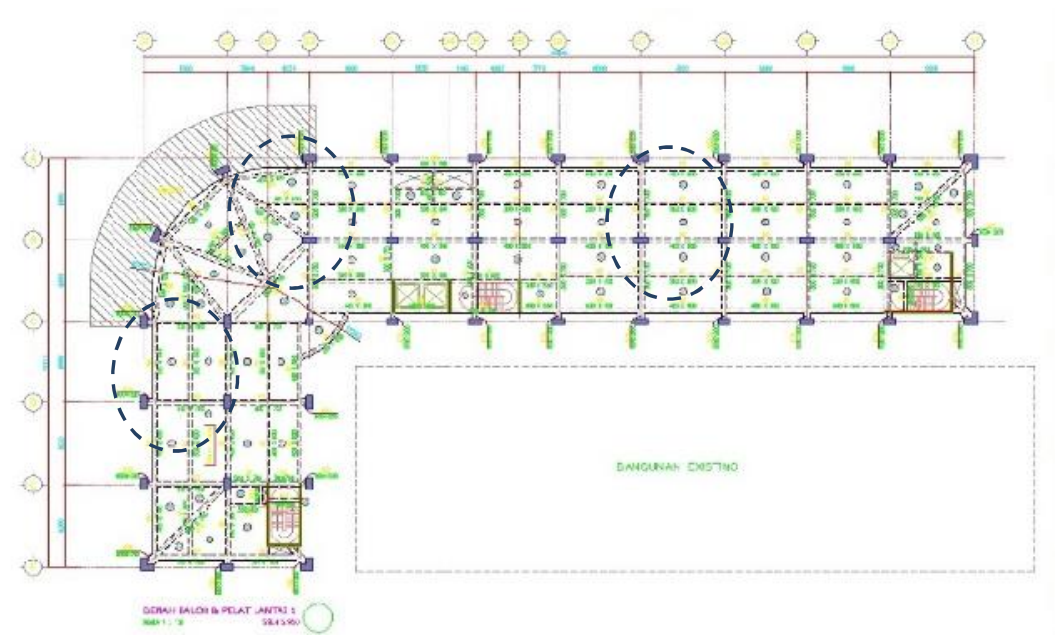

Gambar 7. Posisi Dinding Geser pada Bangunan Gedung 


\section{Evaluasi Non Struktural}

Bagian gedung yang menahan dan meneruskan gaya akibat getaran tanah gempa merupakan elemen struktural, seperti balok, kolom, dinding, dan pelat, sedangkan isi gedung dan elemen lainnya disebut elemen nonstruktural. Sama halnya dengan elemen struktural, elemen nonstruktural perlu didesain agar mampu menahan akibat gempa (gaya inersia dan pergerakan relatif). Lebih jauh, hubungan yang baik diperlukan untuk meneruskan semua gaya dengan aman dari elemen nonstruktural ke elemen struktural.

Evaluasi non dilakukan pada bangunan Gedung Lancang Kuning dilakukan untuk mengetahui kerentanan bangunan gedung pada bagian non strukturnya.

a. Partisi

Bagian atas dinding atau partisi yang berat seperti dinding bata, dan partisi yang ringan seperti papan gipsum dapat terjatuh jika tidak tersambung dengan baik pada plafon bangunan. Partisi pada bangunan Gedung
Lancang Kuning dipasang hingga plafon untuk mengurangi kemungkinan keruntuhan ketika terjadi gempa. Partisi dapat dilihat pada gambar 9 .

b. Perlengkapan Pencahayaan

Pada bangunan gedung ini, peralatan pencahayaan dikaitkan dengan aman pada plafon bangunan, sehingga mencegah jatuhnya peralatan pencahayaan ketika terjadi gempa. Pencahayaan bangunan dapat dilihat pada gambar 10.

c. Railing Tangga

Pada bangunan gedung ini railing tangga menggunakan stainless, sehingga dapat meminimalkan keruntuhan railing yang menghambat proses evakuasi jika terjadi bencana gempa. Railing tangga dapat dilihat pada gambar 11.

d. Detail Tangga

Sambungan antara tangga dan struktur pada bangunan gedung ini bergantung pada beton, sehingga tidak dapat menahan penyimpangan pada lantai.

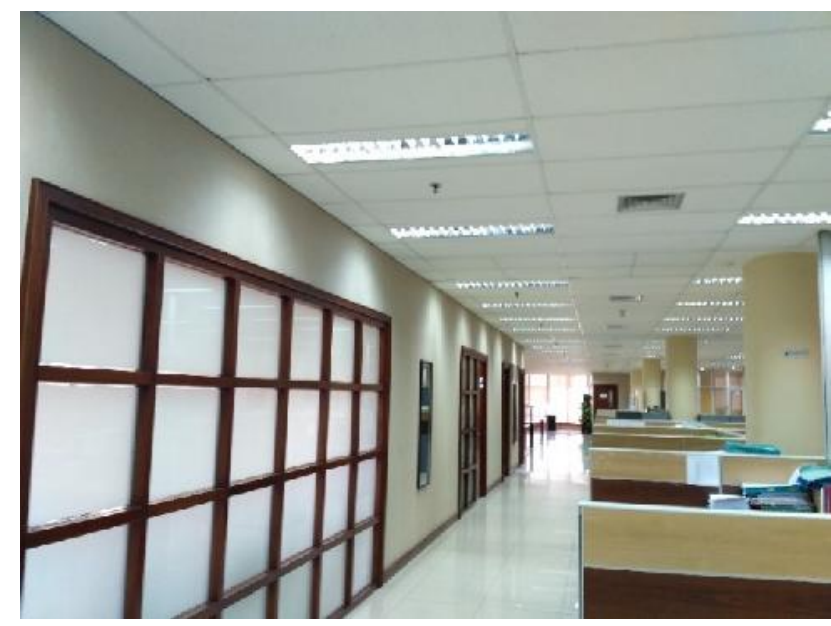

Gambar 8. Partisi pada Bagian Dalam Bangunan Gedung 


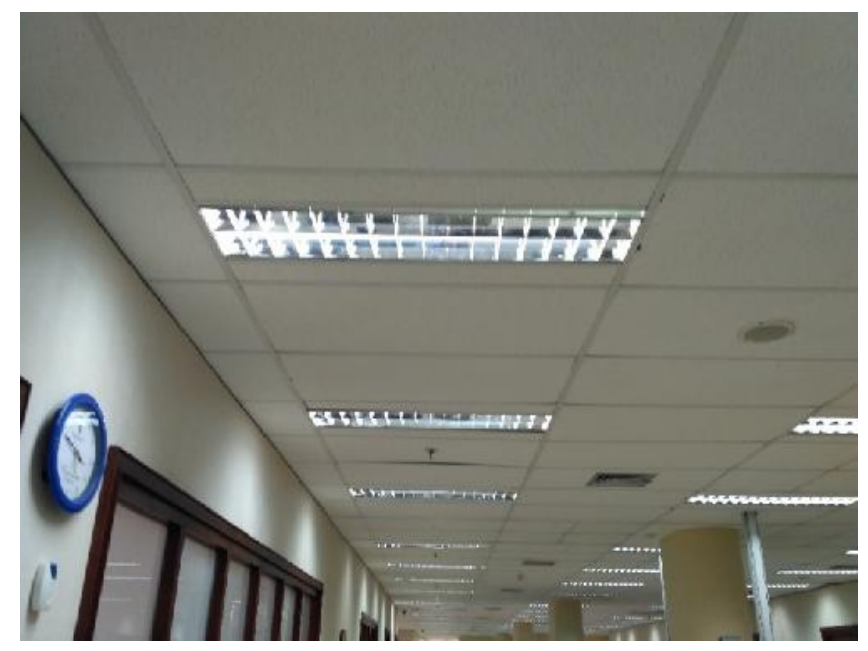

Gambar 9. Pencahayaan Bangunan

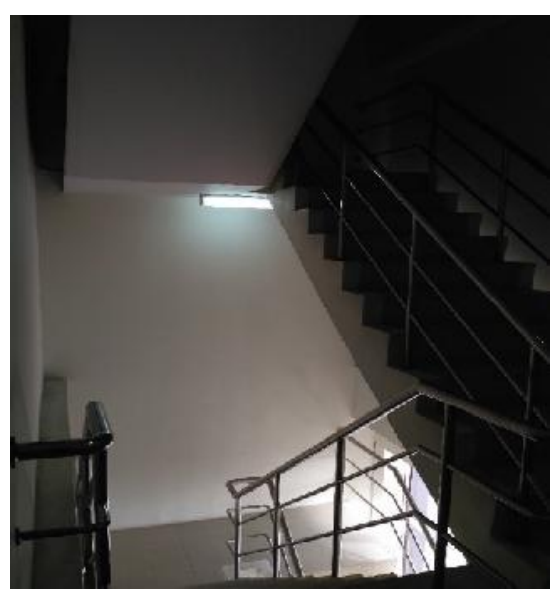

Gambar 10. Railing Tangga

\section{E. KESIMPULAN}

Dari evaluasi Gedung Menara Lancang Kuning terhadap pembebanan gempa dengan menggunakan peraturan American Society of Civil Engineering 41-13 (ASCE 41-13) dapat diambil kesimpulan sebagai berikut :

1. Dari hasil analisis bangunan gedung dengan Evaluasi Tahap 1 standar ASCE 41-13, bahwa bangunan gedung memenuhi tingkat kinerja yang menjadi acuan.

2. Berdasarkan pengamatan visual pada bangunan gedung, bahwa bangunan gedung memenuhi tingkat kinerja sesuai dengan ASCE 41-13.
3. Pada Evaluasi Tahap 1 mengidentifikasi banyak evaluasi struktur dan non struktur sebagai Not Aplicable (N/A). Identifikasi ini bukan berarti bangunan gedung tidak mencapai tingkat kinerja bangunan yang menjadi acuan, namun karena adanya kendala dalam proses evaluasi.

4. Secara keseluruhan hasil evaluasi tahap 1 menunjukkan bahwa Gedung Menara Lancang Kuning tahan terhadap gempa dengan tingkat kinerja Immediate Occupancy. 


\section{DAFTAR PUSTAKA}

Amir F., 2012, Evaluasi Kerentanan Bangunan Gedung Terhadap Gempa Bumi Dengan Rapid Visual Screening (RVS) Berdasarkan FEMA 154, Infrastruktur, Volume 2 Nomor 1 : 9-15.

ASCE 41-13, 2014, Seismic Evaluation and Retrofit of Existing Buildings, American Society of Civil Engineers, Reston, Virginia.

BMKG, 2016, Apakah Gempa Bumi Itu?, Retrieved : October 2, 2016, From :

http://inatews.bmkg.go.id/new/ten tang_eq.php.

Dewobroto W., 2006, Evaluasi Kinerja Bangunan Baja Tahan Gempa dengan SAP2000, Jurnal Teknik Sipil, Volume 3 Nomor 1 : 17-18.

Googlemaps, 2016, Peta Lokasi Gedung Dinas Provinsi Riau, Retrieved : November 12, 2016, From :

https://www.google.co.id/maps/pl ace/Kantor+Gubernur+Riau.

Kurniawandy A., Hendri A., Firdaus R., 2015, Evaluasi Kerentanan Bangunan Gedung Terhadap Gempa Bumi dengan Rapid Visual Screening (RVS) Berdasarkan FEMA 154, Annual Civil Engineering Seminar 2 : 978-979.

Mackenzie, 2015, ASCE 41-13 Structural Evaluation, Pendleton. Puskim.pu.go.id, 2017, Nilai Spektral Percepatan Di Permukaan Dari Gempa Risk-Targeted Maximum
Consider Earthquake Dengan Probabilitas Keruntuhan Bangunan $1 \%$ dalam 50 Tahun, Retrieved : March 25, 2017, From : http://puskim.pu.go.id/Aplikasi/des ain_spektra_indonesia_2011/.

Riauwebdesign, 2016, Kantor Dinas Provinsi Riau, Retrieved : October 24, 2016, From : riauwebdesign.com.

Rohadi S., 2009, Studi Seismotektonik Sebagai Indikator Potensi Gempabumi di Wilayah Indonesia, Jurnal Meteorologi dan Geofisika, Volume 10 Nomor 2 : 111-120.

Santoso E., Widiyantoro S., Sukanta I. N., 2011, Studi Hazard Seismik dan Hubungannya dengan Intensitas Seismik di Pulau Sumatera dan Sekitarnya, Jurnal Meteorologi dan Geofisika, Volume 12 Nomor 2 : 129-136.

Titono M., 2010, Analisa Ketahanan Gempa Dalam Rangka Konservasi Bangunan Bersejarah, Studi Kasus : Gedung $X$, Universitas Indonesia, Depok.

Wood H.O., 1912, The elastic-rebound theory of Earthquakes, by H. F. Reid, University of California Publications, Bulletin of the Department of Geology, June 19, 1911, Bulletin of the Seismological Society of America, Volume 2 Nomor 1 : 98-100, Retrieved From : http://www.bssaonline.org/content /2/1/98.short. 